\title{
A comparative study of the $\boldsymbol{N}$-linked oligosaccharide structures of human IgG subclass proteins
}

\author{
Royston JEFFERIS, ${ }^{*} \|$ John LUND,* Hideki MIZUTANI, $\uparrow$ Hiroaki NAKAGAWA, $\uparrow$ Yutaka KAWAZOE, $\dagger$ \\ Yoji ARATAł and Noriko TAKAHASHI§ \\ * Department of Immunology, University of Birmingham Medical School, Vincent Drive, Edgbaston, Birmingham B15 2TJ, \\ U.K., † Faculty of Pharmaceutical Sciences, Nagoya City University, Mizuho-ku, Nagoya 467, Japan, ‡University of Tokyo, \\ Hongo, Tokyo 113, Japan, and §Nagoya City University College of Nursing, Mizuho-ku, Nagoya 467, Japan
}

\begin{abstract}
Quantitative oligosaccharide profiles were determined for each of 18 human IgG paraproteins representing the four subclasses. Each paraprotein exhibits a unique profile that may be substantially different from that observed for polyclonal IgG. The IgG2 and some IgG3 proteins analysed exhibit a predominance of oligosaccharide moieties having galactose on the $\operatorname{Man}(\alpha 1 \rightarrow 3)$ arm rather than the $\operatorname{Man}(\alpha 1 \rightarrow 6)$ arm; it was previously held that galactosylation of the $\operatorname{Man}(\alpha 1 \rightarrow 6)$ arm is preferred, as observed for IgG1, IgG4 and polyclonal IgG. An IgG4 protein is reported that has galactosylated $\operatorname{Man}(\alpha 1 \rightarrow 3)$ and $\operatorname{Man}(\alpha 1 \rightarrow 6)$ arms on both Fc-localized carbohydrate moieties; previous findings suggested that such fully glycosylated structures could not be accommodated within the internal space of the $\mathrm{C}_{\gamma} 2$ domains. Unusual monoantennary oligosaccharides present in IgG2 and IgG3 proteins were isolated and their structures determined.
\end{abstract}

\section{INTRODUCTION}

Each human immunoglobulin isotype has a characteristic glycosylation profile that may include multiple complex oligosaccharide moieties attached to asparagine residues or simple disaccharides attached through serine or threonine side chains (Pumphrey, 1986). Particular interest is attached to the complex oligosaccharide attached to asparagine-297 of the human IgG gamma heavy chain, which is enclosed between the $\mathrm{C}_{\gamma} 2$ domains and is an integral part of the tertiary/quaternary structure of the Fc region (Deisenhofer, 1981 ; Sutton \& Phillips, 1983). Aglycosylated IgG, obtained by culturing IgG-producing cell lines in the presence of tunicamycin, has been shown to lack several important biological functions, e.g. binding to monocyte $\mathrm{Fc}_{\boldsymbol{\gamma}} \mathbf{R I}$ receptor (Leatherbarrow et al., 1985; Walker et al., 1989), to display decreased complement activation (Nose \& Wigzell, 1983; Leatherbarrow \& Dwek, 1983) and to display increased susceptibility to proteolysis (Leatherbarrow \& Dwek, 1983). However, glycopeptides isolated after proteolytic digestion of IgG have not been demonstrated to have biological activity, e.g. binding to $\mathrm{Fc}$ receptors, $\mathrm{Cl}$ etc. An indirect role is suggested by the intimate involvement of the oligosaccharide with the protein structure; the unpaired $\mathrm{C}_{\gamma} 2$ domains have hydrophobic amino acid side chains (potentially) exposed to the aqueous medium; however, interacțion with the oligosaccharide moiety might prevent such contact. An additional contribution to quaternary structure results from trans interaction(s) between the carbohydrate moieties on each heavy chain. The symmetry of the Fc region requires the two oligosaccharide chains to be accommodated within the restricted space available between the $\mathrm{C}_{\gamma} 2$ domains, and it has been suggested that, for rabbit IgG, this is not possible if each chain is galactosylated (Sutton \& Phillips, 1983). A variety of incompletely glycosylated chains can be accommodated in various combinations, resulting in considerable heterogeneity, as observed for polyclonal IgG and monoclonal IgG. The intimate association of the carbohydrate with the protein structure suggests that such structural heterogeneity (glycoforms) may result in functional heterogeneity. The development of analytical techniques for determining oligosaccharide profiles of IgG molecules has allowed definition of species-distinct glycosylation patterns and revealed heterogeneity of glycosylation within monoclonal proteins (Mizuochi et al., 1982; Rademacher \& Dwek, 1983). Differences in oligosaccharide profiles have been observed between polyclonal IgG isolated from the serum of normal individuals and that from patients with inflammatory diseases (Parekh et al., 1985; Axford et al., 1987; Tomana et al., 1988).

We have applied a recently developed 'mapping' technique (Takahashi et al., 1987; Tomiya et al., 1988) to the analysis of the oligosaccharide structures of a panel of IgG paraproteins representing each subclass. Although each protein shows heterogeneity, its oligosaccharide profile was unique, suggesting that each clone may be characterized by its glycosyltransferase activity. Proteins of the same subclass but differing radically in their glycosylation profiles have been identified (Jefferis et al., 1988).

\section{MATERIALS AND METHODS}

\section{Enzymes and standard oligosaccharides}

$\mathrm{N}$-Oligosaccharide glycopeptidase from almond (obtainable as Glycopeptidase A), $\beta$-galactosidase from Charonia lampas, $\beta$ - $N$ acetylhexosaminidase from jack bean and endo- $\beta$ - $N$-acetylglucosaminidase $\mathrm{D}$ from Diplococcus pneumoniae were purchased from Seikagaku Kogyo Co. $\alpha$-L-Fucosidase from bovine kidney was purchased from Boehringer Mannheim Biochemicals. Pepsin was purchased from Sigma Chemical Co.

Standard biantennary and monoantennary oligosaccharides were prepared from normal IgG by the method of Takahashi $e t$ al. (1987) and Tomiya et al. (1988). The pyridylamino derivatives of the oligosaccharides were prepared and purified as described 
previously (Hase et al., 1984). Gal $\beta 1 \rightarrow 4 \mathrm{GlcNAc} \beta 1 \rightarrow 2 \mathrm{Man}-\alpha-$ $1 \rightarrow 6($ Man $\alpha 1 \rightarrow 3)$ Man $\beta 1 \rightarrow 4$ GlcNAc $\beta 1 \rightarrow 4($ Fuc $\alpha 1 \rightarrow 6)$ Glc-NAcPA (no. 110.3) and $\operatorname{Man} \alpha 1 \rightarrow 6(\mathrm{Gal} \beta 1 \rightarrow 4 \mathrm{GlcNAc} \beta 1 \rightarrow 2 \mathrm{Man}$ $\alpha-1 \rightarrow 3$ ) Man $\beta 1 \rightarrow 4$-GlcNAc $\beta 1 \rightarrow 4($ Fuc $\alpha 1 \rightarrow 6$ )GlcNAc-PA (no. 110.4) were prepared from polyclonal IgG oligosaccharides $F$ and $\mathrm{G}$ respectively by digestion with $\beta$ - $N$-acetylglucosaminidase (Takahashi et al., 1987). GlcNAc $\beta 1 \rightarrow 2$ Man $\alpha 1 \rightarrow 6(\operatorname{Man} \alpha 1 \rightarrow$ 3) Man $\beta 1 \rightarrow 4$ GlcNAc $\beta 1 \rightarrow 4$ (Fuc $\alpha 1 \rightarrow 6$ )GlcNAc-PA (no. 110.1) and $\operatorname{Man} \alpha 1 \rightarrow 6($ GlcNAc $\beta 1 \rightarrow 2 \operatorname{Man} \alpha 1 \rightarrow 3) \operatorname{Man} \beta 1 \rightarrow 4$ GlcNAc $\beta$ $1 \rightarrow 4$ (Fuc $\alpha 1 \rightarrow 6$ )GlcNAc-PA (no. 110.2) were prepared from pyridylamino-oligosaccharides nos. 110.3 and 110.4 respectively by digestion with $\beta$-galactosidase. Gal $\beta 1 \rightarrow 4 \mathrm{GlcNAc} \beta 1 \rightarrow 2 \mathrm{Man}$ $\alpha-1 \rightarrow 6(\operatorname{Man} \alpha 1 \rightarrow 3) \operatorname{Man} \beta 1 \rightarrow 4$ GlcNAc $\beta 1 \rightarrow 4$ GlcNAc-PA (no. $100.3)$ and $\operatorname{Man} \alpha 1 \rightarrow 6(\mathrm{Gal} \beta 1 \rightarrow 4 \mathrm{GlcNAc} \beta 1 \rightarrow 2 \mathrm{Man} \alpha 1 \rightarrow 3)-$ $\operatorname{Man} \beta 1 \rightarrow 4$ GlcNAc $\beta 1 \rightarrow 4$ GlcNAc-PA (no. 100.4) were prepared from pyridylamino-oligosaccharides nos. 110.3 and 110.4 respectively by digestion with $\alpha$-L-fucosidase.

\section{Other chemicals}

The following materials were purchased from the sources indicated: human polyclonal IgG proteins from United States Biochemical Co., Sephadex G-15 from Pharmacia, Bio-Gel P-4 (200-400 mesh) from Bio-Rad Laboratories, sodium cyanoborohydride from Aldrich Chemical Co. and 2-aminopyridine from Wako Pure Chemical Industries.

\section{Preparation of human IgG subclass proteins}

IgG paraproteins were isolated from the sera of patients with multiple myeloma, with an accompanying hypogammaglobulinaemia resulting in polyclonal IgG being diminished to background levels. Sera were dialysed into $0.01 \mathrm{M}$-sodium phosphate buffer, pH 7.0, and eluted as the breakthrough fraction from DEAE-cellulose equilibrated with the same buffer. Some IgG4 proteins bound to the exchanger under these conditions and were eluted with $0.03 \mathrm{M}$-sodium phosphate buffer, $\mathrm{pH}$ 7.0. To generate $\mathrm{Fab}$ and $\mathrm{Fc}$ fragments of IgG4 proteins the purified intact immunoglobulins were dialysed against $0.1 \mathrm{M}$-sodium phosphate buffer, pH 7.0, containing $1 \mathrm{~mm}$-dithiothreitol and 2 mM-EDTA. After digestion with activated (with $1 \mathrm{~mm}$-dithiothreitol for $30 \mathrm{~min}$ at $\left.37^{\circ} \mathrm{C}\right)$ papain $(2 \%, w / w)$ at $37^{\circ} \mathrm{C}$ for $2 \mathrm{~h}$, digestion

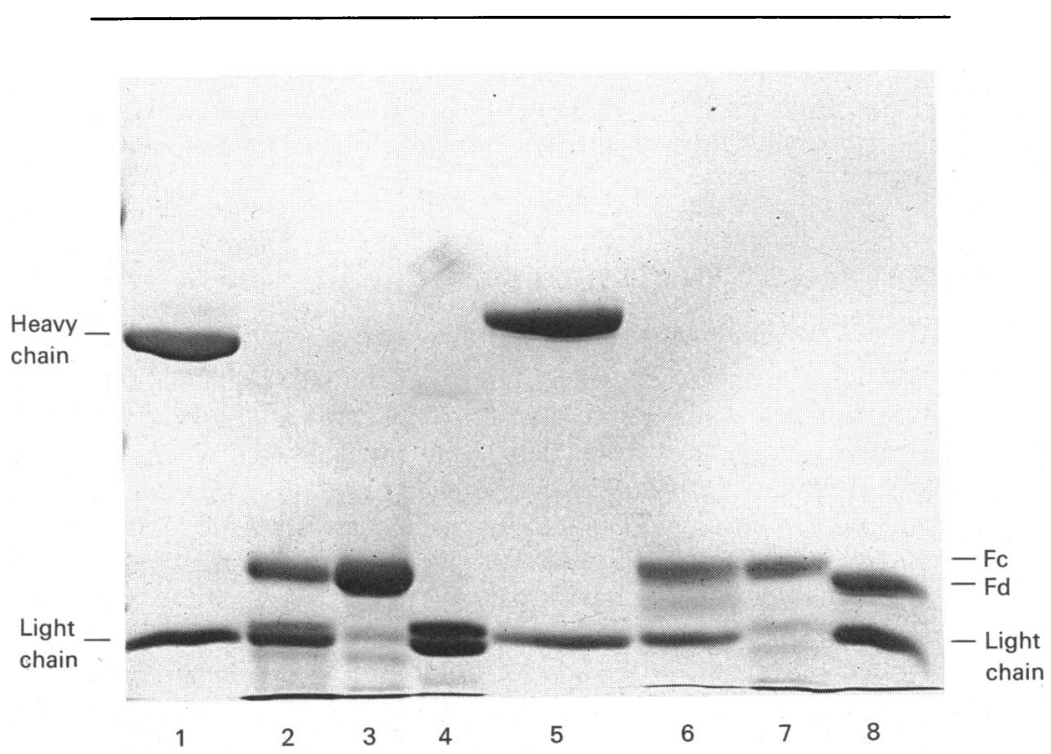

Fig. 1. SDS/PAGE analysis (10\% gel) under reducing conditions of intact IgG4 proteins Rea and AS (tracks 1 and 5), the unseparated papain digests (tracks 2 and 6 ) and their respective purified Fc and Fab fragments (tracks 3 and 7 and tracks 4 and 8) was terminated by the addition of iodoacetamide (10 mM). The digest was dialysed against $0.01 \mathrm{M}$-sodium phosphate buffer, pH 7.3, and passed over a DE52 DEAE-cellulose (Whatman) column equilibrated with the same buffer. The Fab fragment does not bind under these conditions and was recovered in the

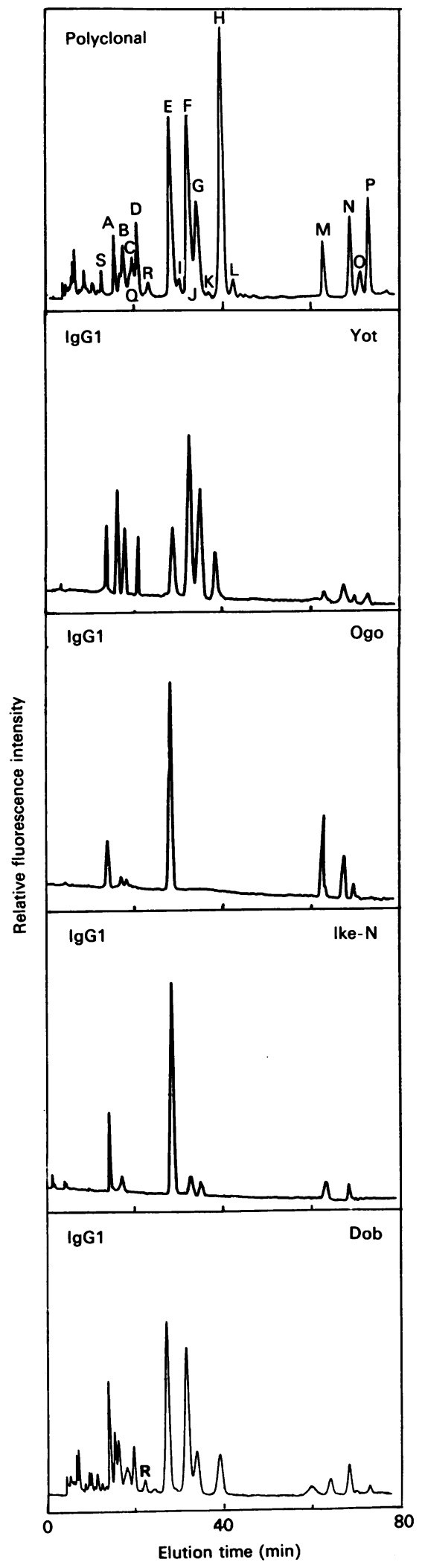


'wash-through' fraction; the Fc was eluted with 0.01 M-sodium phosphate buffer, $\mathrm{pH} 7.3$, containing $0.15 \mathrm{M}-\mathrm{NaCl}$.

The purity of protein preparations was checked by SDS/PAGE analysis on overloaded (approx. $25 \mu \mathrm{g}$ ) gels. Intact proteins gave a single band under non-reducing conditions and two bands corresponding to heavy chains and light chains on reducing gels. Representative results for the IgG4 proteins Rea and AS and their Fab and Fc fragments are shown in Fig. 1.

\section{Preparation of oligosaccharides from IgG}

A 5-10 mg portion of each of the IgG samples was used for the isolation of oligosaccharides. IgG was quantitatively desialylated by mild acid hydrolysis at pH $2(0.01 \mathrm{M}-\mathrm{HCl})$ for $1 \mathrm{~h}$ at $90^{\circ} \mathrm{C}$. Desialylated and pepsin-digested IgG glycopeptides were treated with $N$-oligosaccharide glycopeptidase as described previously (Takahashi et al., 1987). The oligosaccharide fraction was collected by gel filtration on a Bio-Gel P-4 column and further purified by passing it through columns of ion-exchange resins Dowex 50W X8 $\left(\mathrm{H}^{+}\right.$form $)$and Amberlite IRA-400 $\left(\mathrm{CO}_{3}{ }^{2-}\right.$ form) (Nishibe \& Takahashi, 1981).

\section{Isolation of pyridylamino-oligosaccharides by h.p.l.c.}

Oligosaccharide fractions obtained as above were reductively aminated with 2-aminopyridine by the use of sodium cyanoborohydride (Hase et al., 1984). The pyridylamino derivatives of oligosaccharides purified by gel filtration on a Sephadex G-15 column were fractionated and identified by h.p.l.c. with the use of a two-dimensional mapping technique as described previously (Tomiya et al., 1988). Two kinds of column were used, namely a Shimpack CLC-ODS column $(0.6 \mathrm{~cm} \times 15 \mathrm{~cm})$ and a TSKgel Amide- 80 column $(0.46 \mathrm{~cm} \times 25 \mathrm{~cm})$.

\section{Analytical procedures}

Sample proteins were assayed by the orcinol/ $\mathrm{H}_{2} \mathrm{SO}_{4}$ reaction to provide a minimum estimate of neutral sugar content (François et al., 1962); mannose, galactose and, to a lesser extent, fucose contribute to the colour yield, whereas the neutral sugars glucosamine and galactosamine do not. Sialic acids were determined by the method of Hara et al. (1987). The relative quantity $(\%)$ of each component oligosaccharide (A-S) as a proportion of the total carbohydrate of human polyclonal IgG
Table 1. Sialic acid and neutral sugar contents of IgG proteins

\begin{tabular}{lccc}
\hline & $\begin{array}{c}\text { Neutral sugar/ } \\
\text { protein ratio } \\
\text { (mol/mol) }\end{array}$ & $\begin{array}{c}\text { Sialic acid/ } \\
\text { protein ratio } \\
\text { (mol/mol) }\end{array}$ & $\begin{array}{c}\text { Sialic acid/ } \\
\text { neutral } \\
\text { sugar ratio } \\
\text { (mol/mol) }\end{array}$ \\
\hline Polyclonal & 7.91 & 0.59 & 0.075 \\
IgG1 Ike-N & 5.95 & 0.16 & 0.026 \\
IgG1 Ogo & 7.28 & 0.23 & 0.032 \\
IgG2 Ku3 & 8.48 & 0.11 & 0.013 \\
IgG2 INK & 6.60 & 0.31 & 0.047 \\
IgG3 Jir & 9.89 & 0.35 & 0.035 \\
\hline
\end{tabular}

and subclass IgG (Table 2) was determined by integrating the area under each peak and summing these values to determine that for the total carbohydrate content.

\section{RESULTS}

\section{Purity of IgG paraproteins, Fab and Fc fragments}

Results obtained on overloaded SDS/10\%-PAGE gels run under reducing conditions are shown in Fig. 1. The intact proteins yield heavy-chain and light-chain bafits only. The Fc fragments have minor components that are due to papain cleavage at secondary sites within the Fc region. The Fab fragments are essentially pure, yielding light chain and the Fd fragment of the heavy chain.

\section{Oligosaccharide profiles of monoclonal IgG of each subclass}

The $N$-acetylneuraminic (sialic) acid and (minimum) neutral sugar contents of sample proteins are given in Table 1 . The minimum neutral sugar content observed is six residues, consistent with molecules having oligosaccharide moieties on each heavy chain devoid of galactose and fucose, i.e. the orcinol/ $\mathrm{H}_{2} \mathrm{SO}_{4}$ reaction detects the three mannose residues present on each chain only. Sialic acid constitutes a minor proportion of the total sugar content of polyclonal IgG and a lesser proportion for the monoclonal proteins analysed. Detailed oligosaccharide profiles were therefore determined on proteins treated under

Fig. 2. H.p.l.c. profiles of pyridylamino derivatives of oligosaccharide derived from normal IgG (polyclonal) and IgG subclass 1 paraproteins (Yot, Ogo, Ike-N and Dob)

Oligosaccharide fractions obtained by glycopeptidase digestion of the peptic peptides of IgG were aminated and subjected to h.p.l.c. analyses as described in the text. Symbols: G, galactose; M, mannose; F, fucose and GN, $N$-acetylglucosamine. Peak $P$, for example, represents:

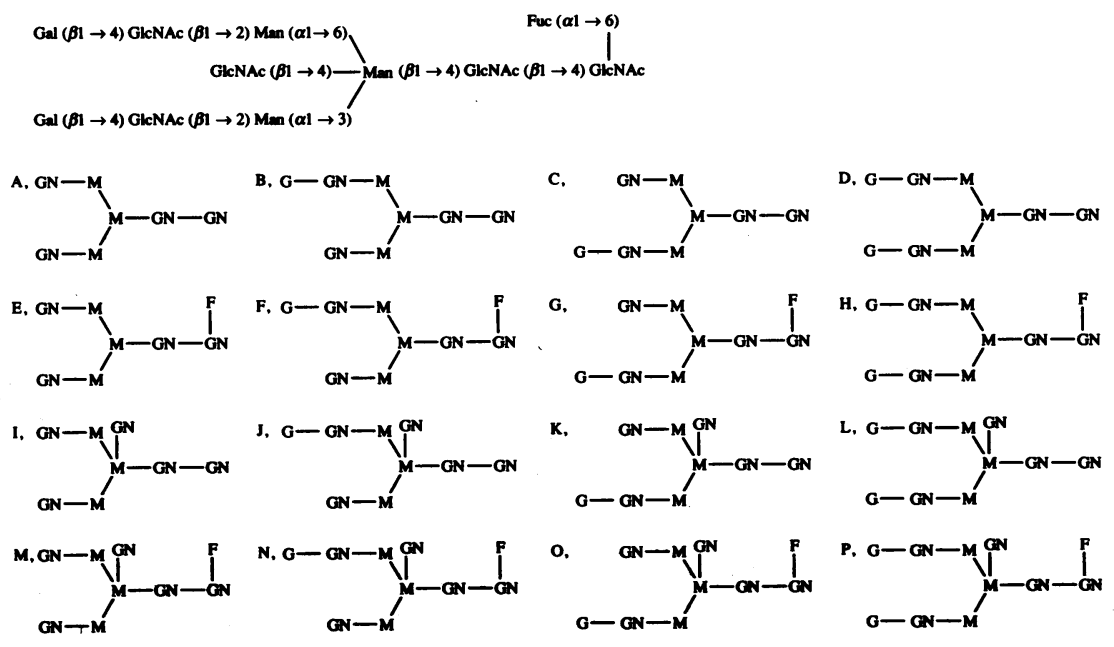




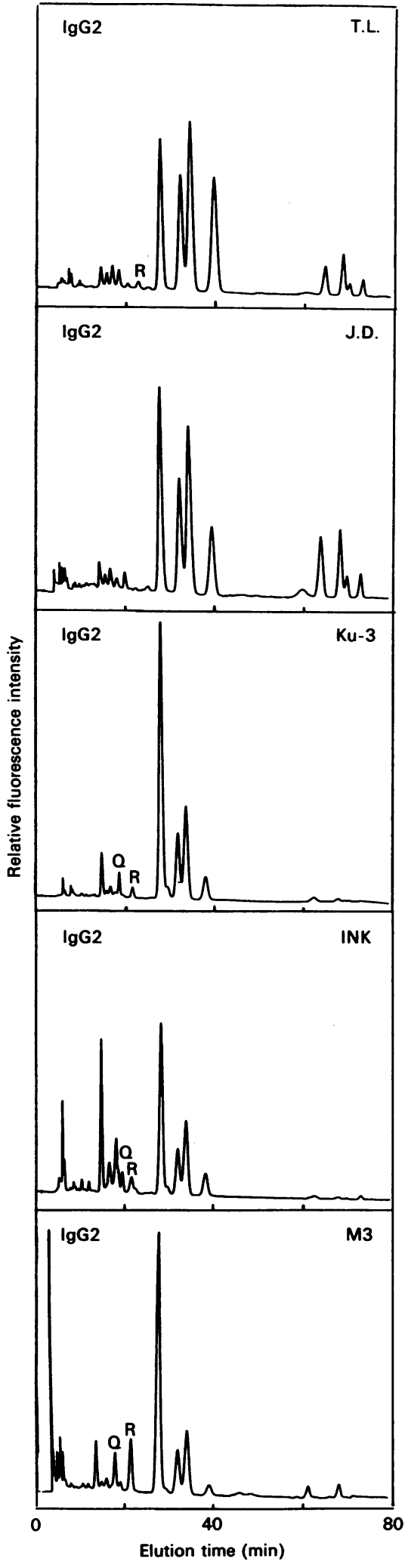

Fig. 3. Comparison of h.p.l.c. profiles of pyridylamino derivatives of oligosaccharides derived from human IgG2 paraproteins T.L., J.D., Ku-3, INK and M3

mild acid conditions to remove sialic acid and simplify the data for interpretation.

Oligosaccharides were released by sequential digestion of IgG subclass proteins $(5-10 \mathrm{mg})$ with pepsin and $\mathrm{N}$-oligosaccharide

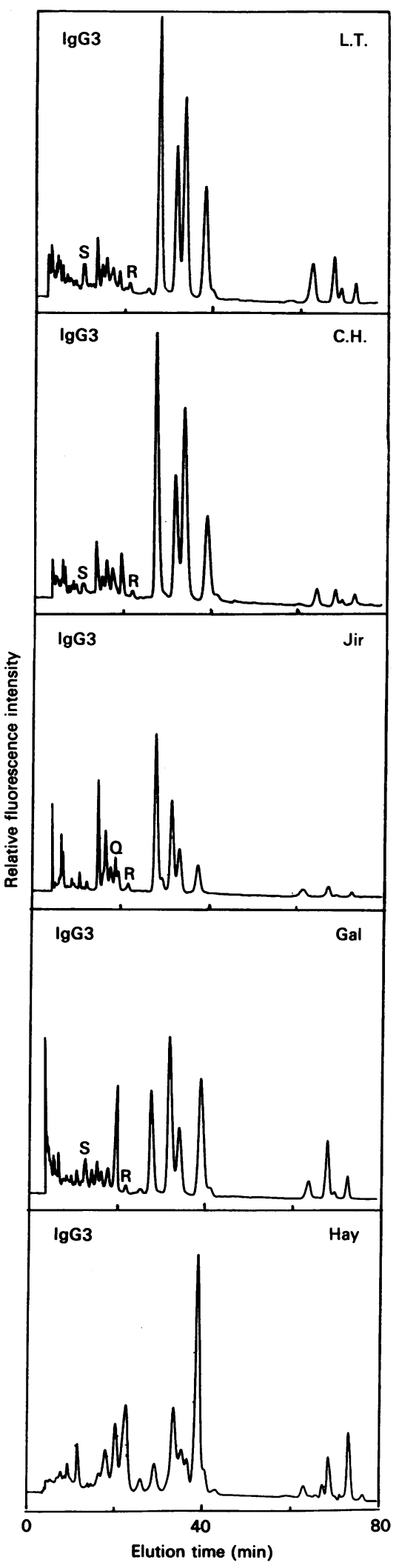

Fig. 4. Comparison of h.p.l.c. profiles of pyridylamino derivatives of oligosaccharides derived from human IgG3 paraproteins L.T., C.H., Jir, Gal and Hay

glycopeptidase (almond); total carbohydrate analysis showed that less than $10 \%$ remained as undigested material (results not shown). The oligosaccharide profiles obtained on octadecyl- 

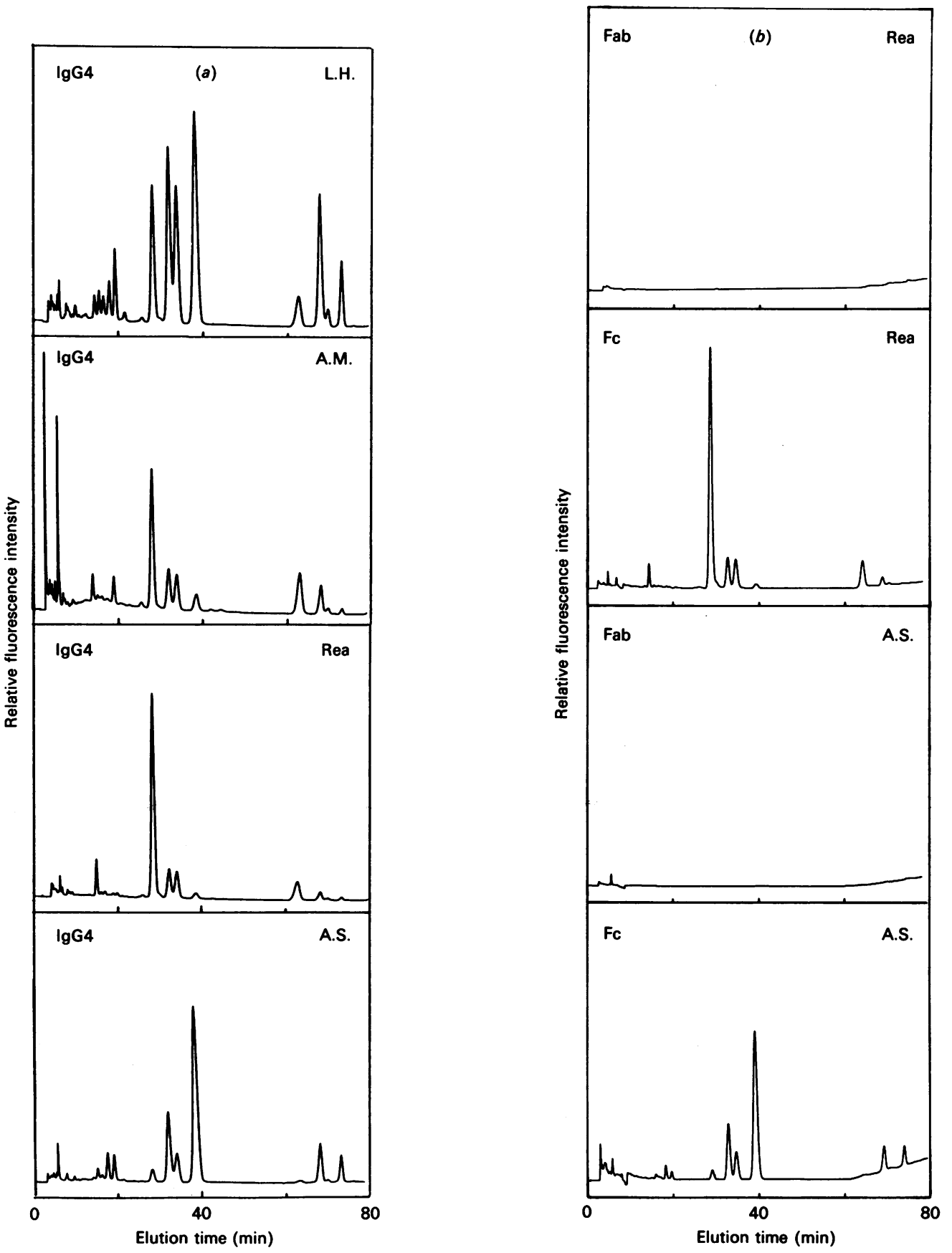

Fig. 5. Comparison of h.p.l.c. profiles of pyridylamino derivatives of oligosaccharides derived from (a) human IgG4 paraproteins L.H., A.M., Rea. and A.S. and (b) Fab and Fc fragments derived from proteins Rea and A.S.

silica (ODS) columns for IgG proteins from each of the four subclasses are shown in Figs. 2-5. Also included in the top of Fig. 2 is the oligosaccharide profile obtained from polyclonal IgG. High-resolution ${ }^{1}$ H-n.m.r. spectroscopy was used together with chemical methods to determine the detailed structures of the separated oligosaccharides A-P in polyclonal IgG (Takahashi et al., 1987). The elution positions of polyclonal oligosaccharides of group I (A-D), group II (E-H), group III (I-L) and group IV (M-P) are indicated. These groups refer to oligosaccharides that are biantennary without fucose, biantennary with fucose, biantennary with bisecting $N$-acetylglucosamine and without fucose and biantennary with bisecting $N$-acetylglucosamine and fucose respectively. Assignments of structures to each of these oligosaccharides are summarized in the legend to Fig. 2. These authentic oligosaccharides were prepared from polyclonal IgG proteins.

It is evident that group II oligosaccharides predominate, with group IV oligosaccharides contributing $2-40 \%$ of the total (Table 2). It is also of interest to note the wide variation in the proportions of the individual group II oligosaccharides within different proteins. Thus the IgG4 proteins Rea and A.S. have $62 \%$ of component $\mathrm{E}$ [lack of galactose on both the $\operatorname{Man}(\alpha 1 \rightarrow 3)$ and $\operatorname{Man}(\alpha 1 \rightarrow 6)$ arms] and $52 \%$ of component $H$ [galactose present on both the $\operatorname{Man}(\alpha 1 \rightarrow 3)$ and $\operatorname{Man}(\alpha 1 \rightarrow 6)$ arms] respectively. In addition, protein A.S. contains components D $(3.7 \%$ ) and $P(6.4 \%)$ (Fig. 2), resulting in $62 \%$ of oligosaccharide moieties having galactose on each arm while $38 \%$ of oligosaccharide moieties have galactose on one arm only or galactose 


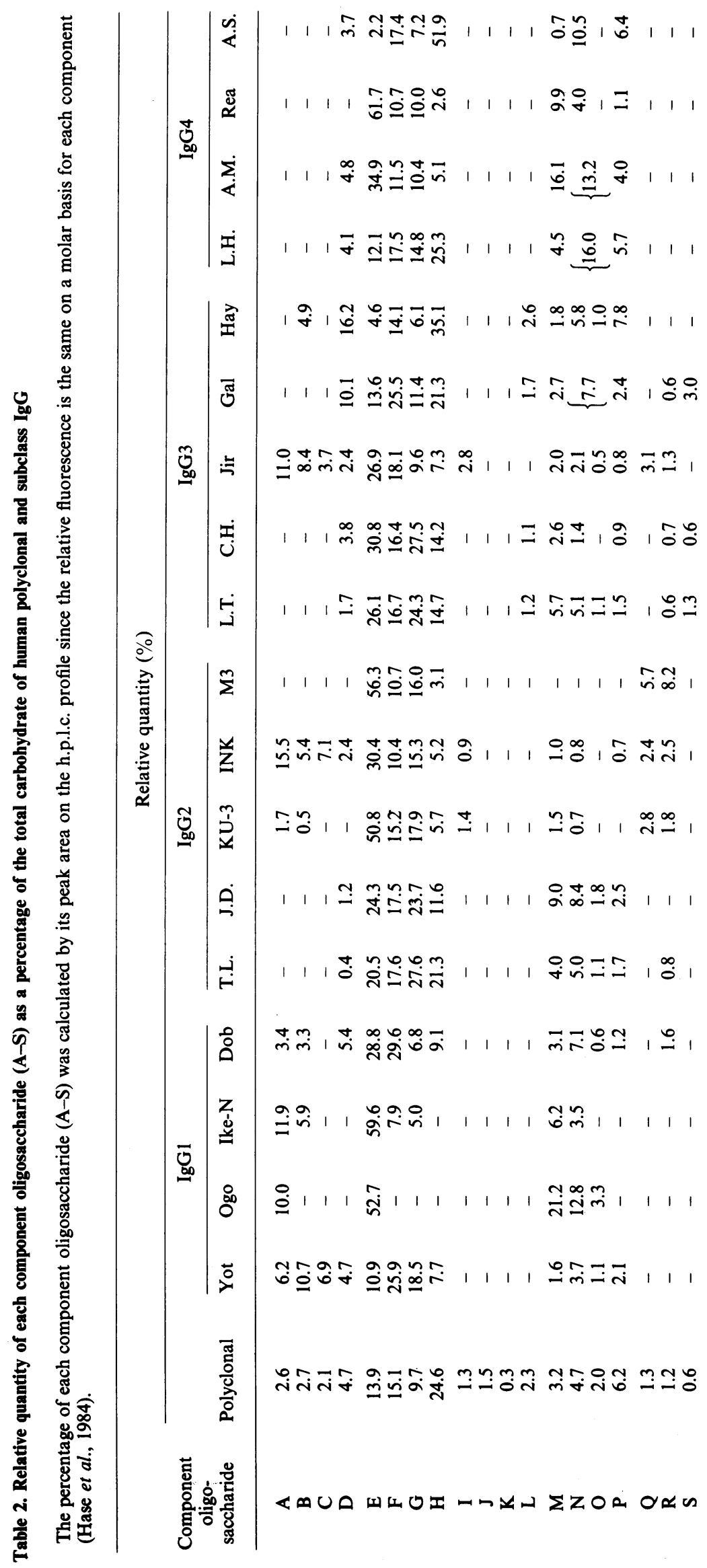


Table 3. Elution positions (glucose units) of standard pyridylamino-oligosaccharides on an octadecyl-silica h.p.l.c. column (Tomiya et al., 1988)

\begin{tabular}{|c|c|c|}
\hline No. & Pyridylamino-oligosaccharide & $\begin{array}{l}\text { Mobility (no. of } \\
\text { glucose units) }\end{array}$ \\
\hline 110.1 & $\begin{array}{r}\mathrm{GN}(\beta 1 \rightarrow 2) \mathrm{M}(\alpha 1 \rightarrow 6) \\
\mathrm{M}(\alpha 1 \rightarrow 3)\end{array}$ & 12.7 \\
\hline 110.2 & $\begin{array}{l}\mathrm{M}(\alpha 1 \rightarrow 6) \\
\mathrm{GN}(\beta 1 \rightarrow 2) \mathrm{M}(\alpha 1 \rightarrow 3)\end{array}$ & 10.2 \\
\hline 110.3 & $\begin{array}{r}\mathrm{G}(\beta 1 \rightarrow 4) \mathrm{GN}(\beta 1 \rightarrow 2) \mathrm{M} \alpha 1 \rightarrow 6) \\
\mathrm{M}(\alpha 1 \rightarrow 3)\end{array} \begin{array}{c}\mathrm{F}(\alpha 1 \rightarrow 6) \\
\mathrm{M}(\beta 1 \rightarrow 4) \mathrm{GN}(\beta 1 \rightarrow 4) \mathrm{GN}\end{array}$ & 13.6 \\
\hline 110.4 & 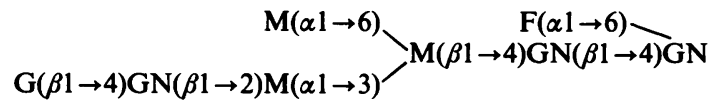 & 10.9 \\
\hline 100.3 & $\begin{array}{r}\mathrm{G}(\beta 1 \rightarrow 4) \mathrm{GN}(\beta 1 \rightarrow 2) \mathrm{M}(\alpha 1 \rightarrow 6) \\
\mathrm{M}(\alpha 1 \rightarrow 3)^{\prime}\end{array}$ & 9.9 \\
\hline 100.4 & $\mathrm{G}(\beta 1 \rightarrow 4) \mathrm{GN}(\beta 1 \rightarrow 2) \mathrm{M}(\alpha 1 \rightarrow 3)$ & 8.0 \\
\hline
\end{tabular}

is absent from both arms. If in an intact molecule these latter $(38 \%)$ oligosaccharides were each paired with a heavy chain bearing galactose on both arms, this would account for $76 \%$ of IgG molecules; the remaining $24 \%$ of IgG molecules would have paired oligosaccharide moieties each having galactose on both the $\operatorname{Man}(\alpha 1 \rightarrow 3)$ and $\operatorname{Man}(\alpha 1 \rightarrow 6)$ arms. This provides a minimum value for the proportion of molecules bearing fully galactosylated oligosaccharide structures.

Oligosaccharides that were clearly separated on octadecylsilica columns for each subclass sample were collected separately. Each subclass IgG oligosaccharide fraction and the corresponding authentic polyclonal IgG oligosaccharide fraction were always processed at the same time and in the same manner, and h.p.l.c. profiles were compared as described below. They were subjected to size fractionation on an amide-silica column. Each set of elution positions on octadecyl-silica and amide-silica columns were plotted on the two-dimensional sugar map prepared with 113 different oligosaccharide standards (Tomiya et al., 1988). The elution positions of oligosaccharides A-P derived from the monoclonal proteins corresponded to authentic oligosaccharides A-P derived from polyclonal IgG, thus allowing unequivocal structural assignment. Indeed, ${ }^{1} \mathrm{H}$-n.m.r.-spectral data for the $\mathrm{H}-1$ and acetyl groups clearly indicate that oligosaccharides $E, F+G, H$ and $M-P$ in protein Yot and oligosaccharides $\mathbf{E}$ and $\mathbf{M}-\mathbf{P}$ in proteins Ogo and Ike-N were demonstrated to give chemical shifts that are consistent with the proposed structures (Takahashi et al., 1987).

\section{Structure of oligosaccharides $\mathbf{Q}, \mathbf{R}$ and $\mathbf{S}$}

Although only very small amounts of the unusual oligosaccharides $Q, R$ and $S$ are present in polyclonal $\operatorname{IgG}$, they are clearly present in IgG2 subclass proteins T.L., Ku-3, INK and M3 and also in IgG3 subclass proteins L.T., C.H., Jir and Gal (Figs. 3 and 4). We prepared the standard oligosaccharides nos. $110.1,110.2,110.3,110.4,100.3$ and 100.4 (Table 3 ) for determining the structure of oligosaccharides $Q, R$ and $S$, as described in the Materials and methods section. Oligosaccharides $\mathbf{Q}, \mathbf{R}$ and $S$ and the standard oligosaccharides were always processed at the same time and in the same manner, and their h.p.l.c. profiles were compared. The elution position (glucose units) on an octadecylsilica column of each pair of oligosaccharides with the same molecular size, oligosaccharides nos. 110.1 and 110.2, oligosaccharides nos. 110.3 and 110.4 and oligosaccharides nos. 100.3 and 100.4 , can be used to distinguish clearly between substituted and unsubstituted $\operatorname{Man}(\alpha 1 \rightarrow 3)$ residues (Table 3). The elution positions of oligosaccharides $\mathbf{Q}, \mathbf{R}$ and $\mathbf{S}$ on an octadecyl-silica column coincided with those of standard oligosaccharides nos.
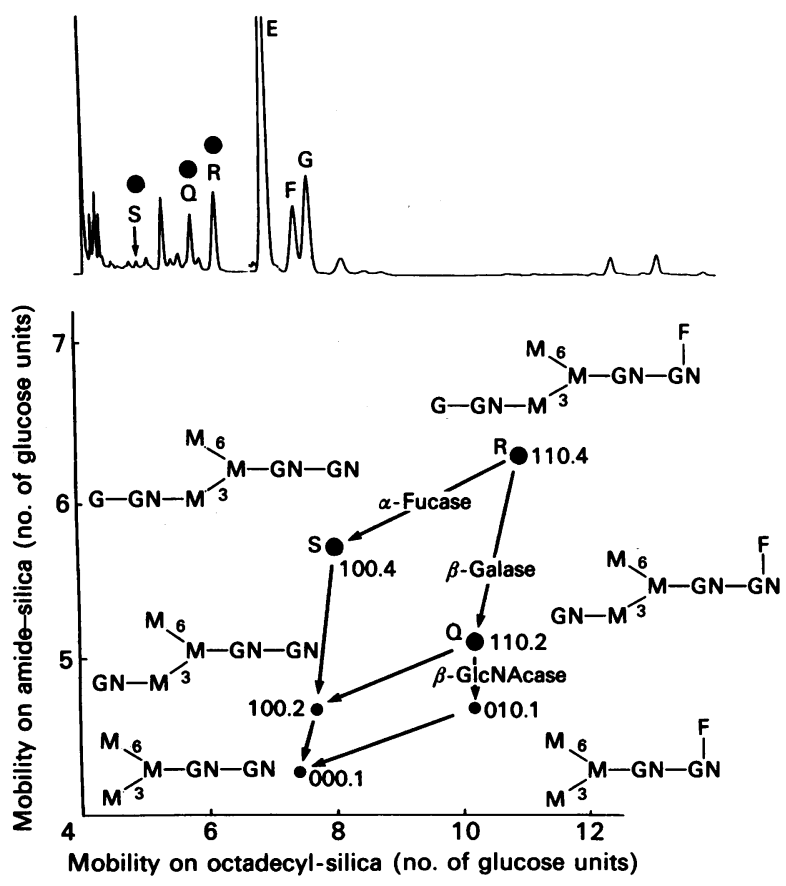

Fig. 6. Determination of structures of oligosaccharides $Q, R$ and $S$ by using the two-dimensional sugar map method

The co-ordinates of oligosaccharides $Q, R$ and $S$ were superimposed on the co-ordinates of the standard oligosaccharides nos. 110.2, 110.4 and 100.4 respectively on the sugar map. Arrows indicate the direction of changes of the co-ordinates of oligosaccharides after digestion by $\alpha$-fucosidase ( $\alpha$-Fucase), $\beta$-galactosidase ( $\beta$-Galase) and $\beta$ - $N$-acetylhexosaminidase ( $\beta$-GlcNAcase). 


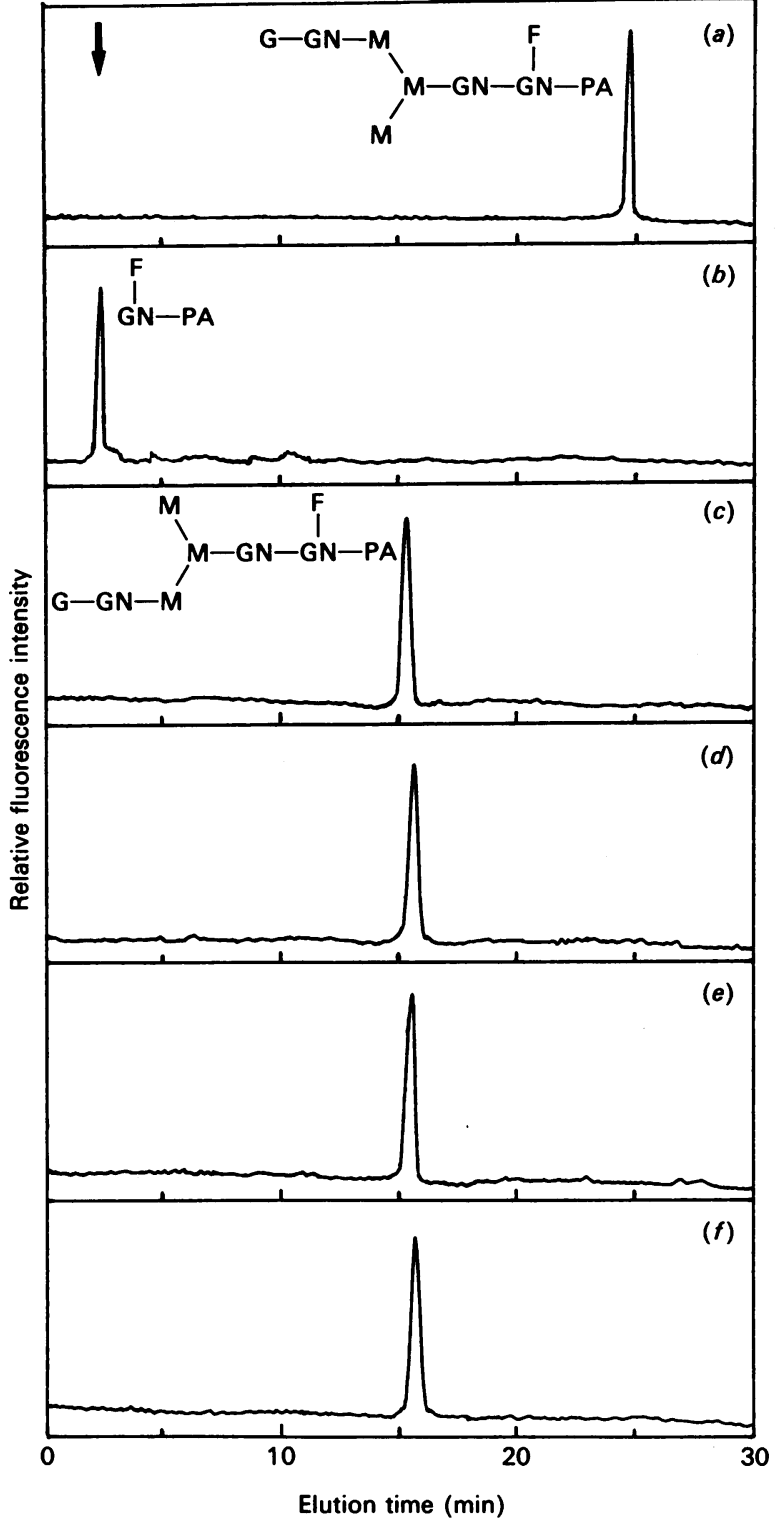

Fig. 7. H.p.l.c. analyses on an octadecyl-silica column of endo- $\beta-N$-acetylglucosaminidase D digestion of pyridylamino-oligosaccharides nos. 110.3 and 110.4 derived from polyclonal IgG and of pyridylamino-oligosaccharide $R$ from IgG2 and IgG3

(a) Pyridylamino-oligosaccharide no. 110.3 on an octadecyl-silica column; (b) pyridylamino-oligosaccharide no. $110.3(300 \mathrm{pmol})$ digested with 20 munits of endo- $\beta$ - $N$-acetylglucosaminidase D; (c) pyridylamino-oligosaccharide no. $110.4 ;(d)$ pyridylamino-oligosaccharide no. $110.4(300 \mathrm{pmol})$ digested with 20 munits of endo- $\beta$ $N$-acetylglucosaminidase $\mathrm{D} ;(e)$ pyridylamino-oligosaccharide $\mathrm{R}$ from IgG2 and IgG3; $(f)$ pyridylamino-oligosaccharide $\mathrm{R}$ digested with endo- $\beta-N$-acetylglucosaminidase $D$ in the same conditions as above. The arrow indicates the position of the standard pyridylamino derivative of $\operatorname{Fuc}(\alpha 1 \rightarrow 6)$ GlcNAc.

$110.2,110.4$ and 100.4 (Tomiya et al., 1988) respectively. The oligosaccharides $Q, R$, and $S$ were separately subjected to size fractionation by h.p.l.c. (amide-silica column). Oligosaccharides $\mathbf{Q}, \mathbf{R}$ and $\mathbf{S}$ were again eluted at the same positions as those of the standard oligosaccharides nos. 110.2, 110.4 and 100.4 respectively. As shown in Fig. 6, oligosaccharide $R$ was converted into oligosaccharide $Q$ after $\beta$-galactosidase digestion, and into oligosaccharide $S$ after $\alpha$-L-fucosidase digestion. Oligosaccha-

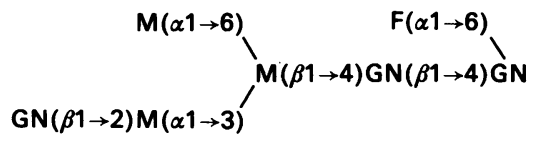

$\mathbf{R}$

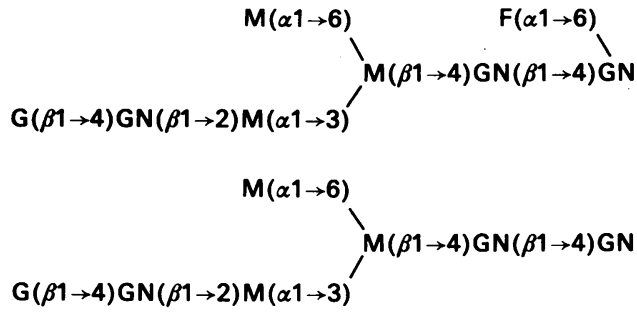

Fig. 8. Proposed structures of oligosaccharides $Q, R$ and $S$

rides $\mathbf{Q}, \mathbf{R}$ and $\mathbf{S}$ were all converted into a common trimannosyl core

$$
\underset{\mathrm{M}(\alpha 1 \rightarrow 3)}{\mathrm{M}(\alpha 1 \rightarrow 6)} \mathrm{M}(\beta 1 \rightarrow 4) \mathrm{GN}(\beta 1 \rightarrow 4) \mathrm{GN}
$$

after $\beta$ - $N$-acetylhexosaminidase and $\alpha$-L-fucosidase digestion of oligosaccharide $\mathrm{Q}, \beta$-galactosidase, $\beta$ - $N$-acetylhexosaminidase and $\alpha$-L-fucosidase digestion of oligosaccharide $\mathbf{R}$ and $\beta$ galactosidase and $\beta$ - $N$-acetylhexoxaminidase digestion of oligosaccharide $\mathbf{S}$.

Further characterization was achieved after endo- $\beta$ - $N$-acetylglucosaminidase D digestion (Tai et al., 1975). A $300 \mathrm{pmol}$ portion of each of oligosaccharides nos. 110.3 and 110.4 was separately digested with 20 munits of endo- $\beta$ - $N$-acetylglucosaminidase $\mathrm{D}$ at $\mathrm{pH} 6.5$, and the reaction products were analysed by the h.p.l.c. procedure (Fig. 7). The sugar residue essential for the action of endo- $\beta-N$-acetylglucosaminidase $\mathrm{D}$ has been identified as an unsubstituted $\alpha$-mannosyl residue linked to the innermost $\beta$-mannosyl residue by $(\alpha 1 \rightarrow 3)$-linkage (Tai et al., $1975)$. It was observed that on treatment with endo- $\beta$ - $N$-acetylglucosaminidase $\mathrm{D}$ the pyridylamino derivative of oligosaccharide no. 110.3 disappears and a new peak appears at a position that coincides with that of the pyridylamino derivative of Fuc $(\alpha 1 \rightarrow 6)$ GlcNAc (see Figs. $7 a$ and $7 b$ ). By contrast, no change was observed in oligosaccharide no. 110.4 (Figs. $7 c$ and $7 d$ ) or in oligosaccharide $\mathbf{R}$ (Figs. $7 e$ and $7 f$ ). This result clearly indicates that the $\operatorname{Man}(\alpha 1 \rightarrow 3)$ residue is substituted in oligosaccharides no. 110.4 and $R$. This situation is the same as the case of two sets of oligosaccharides that have the same molecular size, oligosaccharides no. 110.1, no. 110.2 and $Q$ and oligosaccharides no. 100.3, no. 100.4 and $S$. This indicates that oligosaccharides $Q, R$ and $S$ possess a $\operatorname{Gal}(\beta 1 \rightarrow 4) G l c N A c$ group linked to a $\operatorname{Man}(\alpha 1 \rightarrow 3)$ residue. The structures proposed on the basis of these results for oligosaccharides $Q, R$ and $S$ are summarized in Fig. 8. Determination of n.m.r. structures for oligosaccharides $\mathbf{Q}, \mathbf{R}$ and $\mathrm{S}$ was not feasible because they were minor components and insufficient material was available.

\section{DISCUSSION}

Recently developed techniques for determining oligosaccharide structures present in glycoproteins (Takahashi et al., 1987; Tomiya et al., 1988) have been applied to the analysis of purified monoclonal human IgG proteins of each of the four IgG subclasses. In all samples group II oligosaccharide structures, which correspond to biantennary structures with fucose, predominate (Figs. 2-5). Peaks E, F, G and H represent oligo- 
saccharides without galactose and having galactose on the $\operatorname{Man}(\alpha 1 \rightarrow 6)$ arm only, on the $\operatorname{Man}(\alpha 1 \rightarrow 3)$ arm only and on both the arms respectively. It is apparent that each paraprotein has a unique oligosaccharide profile and that the relative proportions of structures E, F, G and $\mathrm{H}$ differ widely. Three broad patterns of glycosylation may be discerned: (1) proteins in which structure E predominates (Ogo, Ike-N, Ku-3, M3, A.M. and Rea), (2) proteins in which structures $\mathrm{E}, \mathrm{F}, \mathrm{G}$ and $\mathrm{H}$ are each present in significant quantity (Yot, Dob, T.L., J.D., INK, L.T., C.H., Jir, Gal and L.H.) and (3) proteins in which structure $\mathrm{H}$ predominates (Hay and A.S.). These differing patterns of galactosylation presumably reflect differences in the activity of galactosyltransferases and processing enzymes within the clones of cells synthesizing the respective proteins.

It is of interest to compare and contrast the glycosylation patterns of the IgG4 proteins Rea and A.S. (Table 2), in which components $\mathrm{E}$ and $\mathrm{H}$ predominate respectively. Analysis of $\mathrm{Fab}$ and Fc fragments generated from these proteins show that carbohydrate was attached within the Fc region only and will therefore be linked through asparagine-297. The sum of components D.H. and P for protein A.S. gives a total of $62 \%$ of oligosaccharide components with galactose on both the $\operatorname{Man}(\alpha 1 \rightarrow 3)$ and $\operatorname{Man}(\alpha 1 \rightarrow 6)$ arms. This suggests that a minimum of $24 \%$ of molecules have digalactosylated oligosaccharide moieties on both heavy chains. Analysis of rabbit Fc has suggested that such structures cannot be accommodated within the inter $\mathrm{C}_{\gamma} 2$ domain space and that one $\operatorname{Man}(\alpha 1 \rightarrow 3)$ arm is always devoid of galactose (Sutton \& Phillips, 1983; Rademacher \& Dwek, 1983). It is possible that accommodating such structures requires a change in the protein conformation.

It is noteworthy that in polyclonal IgG, IgG1 and IgG4 proteins oligosaccharide $\mathrm{F}$ is always present in greater amount than oligosaccharide $G$. This has been interpreted to suggest that galactosylation occurs preferentially on the $\operatorname{Man}(\alpha 1 \rightarrow 6)$ arm of the biantennary complex. However, in all IgG2 proteins analysed and two (out of five) IgG3 proteins oligosaccharide $G$ predominates over oligosaccharide $F$. These results suggest that the galactosyltransferase transfers galactose to the $\mathrm{N}$-acetylglucosamine attached to the $\operatorname{Man}(\alpha 1 \rightarrow 3)$ residue in preference to the $\operatorname{Man}(\alpha 1 \rightarrow 6)$ residue. The unusual monoantennary oligosaccharides $\mathrm{Q}, \mathbf{R}$ and $\mathrm{S}$, which lack $N$-acetylglucosamine bonded to the $\operatorname{Man}(\alpha 1 \rightarrow 6)$ residue, were also detected in subclass 2 or 3 proteins only. These results suggest a lower activity for $N$ acetylglucosaminyltransferase in IgG2-subclass-producing and
IgG3-subclass-producing plasma cells. The presence of oligosaccharide structures $Q, R$ and $S$ in human $I g G$ is demonstrated for the first time in this study.

We thank Miss Tracy Bentley for her excellent technical assistance. This work was supported in part from the Ministry of Education, Science and Culture of Japan. R.J. gratefully acknowledges the Japan Society for the Promotion of Science and The Royal Society (U.K.) for financial support for a study visit.

\section{REFERENCES}

Axford, J. S., Lydyard, P. M., Isenberg, D. A., Mackenzie, L., Hay, F. C. \& Roitt, I. M. (1987) Lancet ii, 1486-1488

Deisenhofer, J. (1981) Biochemistry 20, 2361-2370

François, C., Marshall, R. D. \& Neuberger, A. (1962) Biochem. J. 83, 335-341

Hara, S., Takemori, Y., Yamaguchi, M., Nakamura, M. \& Okhura, Y. (1987) Anal. Biochem. 164, 138-145

Hase, S., Ibuki, T. \& Ikenaka, T. (1984) J. Biochem. (Tokyo) 95, 197-203

Jefferis, R., Cranmer, S., Arata, Y. \& Takahashi, N. (1988) Biochem. Soc. Trans. 16, 340-341

Leatherbarrow, R. J. \& Dwek, R. A. (1983) FEBS Lett. 164, 227-230

Leatherbarrow, R. J., Rademacher, T. W., Dwek, R. A., Woof, J. M., Clark, A., Burton, D. R., Richardson, N. E. \& Feinstein, A. (1985) Mol. Immunol. 22, 407-415

Mizuochi, T., Taniguchi, T., Shimizu, A. \& Kobata, A. (1982) J. Immunol. 129, 2016-2020

Nishibe, H. \& Takahashi, N. (1981) Biochim. Biophys. Acta 661, 274-279

Nose, M. \& Wigzell, H. (1983) Proc. Natl. Acad. Sci. U.S.A. 80, $6632-6636$

Parekh, R. B., Dwek, R. A., Sutton, B. J., Fernandes, D. L., Leung, A., Stanworth, D., Rademacher, T. W., Mizuochi, T., Taniguchi, T., Matsuta, K., Takeuchi, F., Nagano, Y., Miyamoto, T. \& Kobata, A. (1985) Nature (London) 316, 452-457

Pumphrey, R. S. H. (1986) Immunol. Today 7, 174-178

Rademacher, T. W. \& Dwek, R. A. (1983) Prog. Immunol. 5, 95-112

Sutton, B. J. \& Phillips, D. C. (1983) Biochem. Soc. Trans. 11, 130-132

Tai, T., Yamashita, K., Arakawa, M., Koide, N., Muramatsu, T., Iwashita, S., Inoue, Y. \& Kobata, A. (1975) J. Biol. Chem. 250, 8569-8575

Takahashi, N., Ishii, I., Ishihara, H., Mori, M., Tejima, S., Jefferis, R., Endo, S. \& Arata, Y. (1987) Biochemistry 26, 1137-1144

Tomana, M., Schrohenloher, R. E., Koopman, W. J., Alarcon, G. S. \& Paul, W. A. (1988) Arthritis Rheum. 31, 333-338

Tomiya, N., Awaya, J., Kurono, M., Endo, S., Arata, Y. \& Takahashi, N. (1988) Anal. Biochem. 171, 73-90

Walker, M. R., Lund, J., Thompson, K. M. \& Jefferis, R. (1989) Biochem. J. 259, 347-353 